$\underset{\text { clinical }}{\text { nephron }}$

Practice
Nephron 2017;137:277-281

DOI: 10.1159/000477218
Received: March 7, 2017

Accepted after revision: May 2, 2017

Published online: June 9, 2017

\title{
Nonpharmacological, Biomechanical Approaches to Control Inflammation in Acute Kidney Injury
}

\author{
Shinji Tanaka ${ }^{a}$ Tsuyoshi Inoue $^{a}$ John A. Hossack ${ }^{b}$ Mark D. Okusa ${ }^{a}$ \\ a Division of Nephrology and Center for Immunity, Inflammation, and Regenerative Medicine, and \\ ${ }^{b}$ Department of Biomedical Engineering, University of Virginia Health System, Charlottesville, VA, USA
}

\section{Keywords}

Acute kidney injury · Ischemia-reperfusion · Vagus nerve stimulation · Pulsed ultrasound · Optogenetics · Cholinergic anti-inflammatory pathway

\begin{abstract}
Inflammation is broadly recognized as an important factor in the pathogenesis of acute kidney injury (AKI), but pharmacological approaches to alleviate inflammation in AKI have been without success in clinical trials. Neuromodulation by nonpharmacological methods is emerging as a novel therapeutic strategy to treat inflammatory diseases. Recently, our group and others have demonstrated that vagus nerve stimulation and pulsed ultrasound ameliorated inflammation via the cholinergic anti-inflammatory pathway (CAP) in various animal models, including renal ischemia-reperfusion injury. Delineating the precise mechanisms by which these methods activate the CAP and ameliorate inflammation is mandatory for the broad clinical application in the future. Novel techniques, such as optogenetics, are expected to elucidate these complex mechanisms.

(c) 2017 S. Karger AG, Basel
\end{abstract}

\section{Introduction}

Acute kidney injury (AKI) is a serious clinical disorder because it is strongly associated with high mortality and AKI episodes may lead to chronic kidney disease and end-stage renal disease. Supportive therapy is currently the only treatment strategy for AKI, and no drug (therapeutic or preventive) is approved for AKI treatment in humans [1]. Despite our understanding of mechanisms responsible for inflammation in the pathogenesis of AKI, pharmacological approaches in clinical trials to alleviate inflammation have been without success [2]. Thus, other approaches are eagerly sought to ameliorate inflammation in AKI. Among these approaches, neuromodulation by nonpharmacological

Contribution from the AKI \& CRRT 2017 Symposium at the 22nd International Conference on Advances in Critical Care Nephrology, Manchester Grand Hyatt, San Diego, CA, USA, March 7-10, 2017. This symposium was supported in part by the NIDDK funded University of Alabama at Birmingham-University of California San Diego O'Brien Center for Acute Kidney Injury Research (P30 DK079337).

\section{KARGER}

(c) 2017 S. Karger AG, Basel 
methods is emerging as a powerful approach to counter inflammation, as many studies have revealed neural pathways that regulate inflammation and immunity [3]. In this review, we discuss several nonpharmacological approaches to modulate the neuroimmune axis and alleviate inflammation as a promising treatment strategy against AKI.

\section{The Inflammatory Reflex}

In 1995, Watkins et al. [4] reported that subdiaphragmatic vagal transection abolished hyperthermia following intraperitoneal injection of interleukin- $1 \beta$, demonstrating that peripheral inflammation activates the afferent vagus nerve to initiate a fever response. Subsequently, Tracey et al. [3] found that a small amount of CNI-1493 (a potent anti-inflammatory agent), which had been previously demonstrated by Kramer et al. [5] to ameliorate the distant lung inflammation during AKI through systemic administration, administered via the intracerebroventricular route decreased not only the level of brain tumor necrosis factor (TNF) but also that of plasma TNF, which originates mostly from the spleen, in lipopolysaccharide-treated rats [6]. They also demonstrated that severing the vagus nerve abolished the decrease in plasma TNF level by CNI-1493 administration and that only electrical stimulation of the vagus nerve was enough to reduce plasma TNF. This result suggested that signals descend from the brain through the vagus nerve to the spleen to block inflammation. Thus, the principle forming "the inflammatory reflex" is that the afferent vagus nerve senses peripheral inflammatory stimulation and the signal is transmitted to the efferent vagus nerve to abrogate inflammation in the peripheral.

The inflammatory reflex is characterized by several mechanisms summarized in online supplementary Figure 1 (see www.karger.com/doi/10.1159/000477218). (1) The afferent vagus nerve is stimulated by inflammatory products, including cytokines, damage-associated molecular patterns, and pathogen-associated molecular patterns, through cytokine receptors and pattern-recognition receptors expressed in the vagus nerve [7]. (2) The nerve activity is transmitted to the brain, resulting in the activation of the efferent vagus nerve. (3) The signal is relayed to the splenic nerve [8]. (4) Norepinephrine released from the splenic nerve interacts with $\beta 2$-adrenergic receptors in choline acetyltransferase-positive $\mathrm{T}$ cells in the spleen, causing acetylcholine $(\mathrm{ACh})$ release from these T cells [9]. (5) ACh interacts with $\alpha 7$ nicotinic ACh receptors ( $\alpha 7 \mathrm{nAChRs}$ ) in macrophages residing close to choline acetyltransferase-positive $\mathrm{T}$ cells, resulting in suppressed proinflammatory cytokine production and inflammation [10]. The efferent arm of the inflammatory reflex is termed the cholinergic anti-inflammatory pathway (CAP) [3].

\section{Nonpharmacological Strategies to Control Inflammation in AKI}

\section{Vagus Nerve Stimulation}

We recently demonstrated that vagus nerve stimulation (VNS) $24 \mathrm{~h}$ before renal ischemia dramatically protected the kidney from renal ischemia-reperfusion injury (IRI) [11]. It is interesting that stimulating the central end (afferent VNS) or the peripheral end of the cut vagus nerve had comparable renoprotective effects against the stimulation of the intact vagus nerve. The mechanism responsible for the protective effect of afferent VNS is likely to be more complex than a vago-vagal response because stimulating the afferent limb was still protective when the contralateral vagus was anesthetized and presumably nonconductive. These unknown pathways in the brain following afferent VNS clearly merit further investigation. VNS was also reported to be beneficial to decrease chronic allograft nephropathy with reduced immune cell infiltration [12].

Many clinical trials are underway to translate the protective effect of VNS into treatment for patients with inflammatory and autoimmune diseases (110 studies on ClinicalTrials.gov using "vagus nerve stimulation"; https://clinicaltrials.gov [accessed March 3, 2017]). In patients with rheumatoid arthritis, vagus nerve activity was significantly lower than that in controls [13]. In addition, serum high mobility group box 1 levels and vagus nerve activity showed a significant inverse association. These data suggest that decreased CAP activity is associated with disease activity and that activation of CAP may be beneficial in these patients. The first clinical trial that used an implanted electronic device in patients with refractory rheumatoid arthritis was recently reported [14]. VNS significantly inhibited TNF production and improved disease severity for up to 84 days. The effectiveness of VNS has also been demonstrated in patients with Crohn's disease $[15,16]$. These results showed that VNS can reduce inflammation in humans, offering a promising view of the usefulness of VNS for other inflammatory diseases, including AKI. 
Fig. 1. The inflammatory reflex. The inflammatory reflex originally consisted of the afferent/efferent vagus nerve, splenic nerve, choline acetyltransferase (ChAT)-positive T cells expressing $\beta 2$-adrenergic receptors, and macrophages expressing $\alpha 7$ nicotinic acetylcholine receptors ( $\alpha 7 \mathrm{nAChRs).} \mathrm{Re-}$ cent studies have shown that the reflex is much more complicated than what it was before (e.g., a sympathetic route in the stimulation of $\mathrm{C} 1$ neurons). ACh, acetylcholine; CNS, central nervous system; DMV, dorsal motor nucleus of the vagus; NE, norepinephrine; NTS, nucleus tractus solitarius.

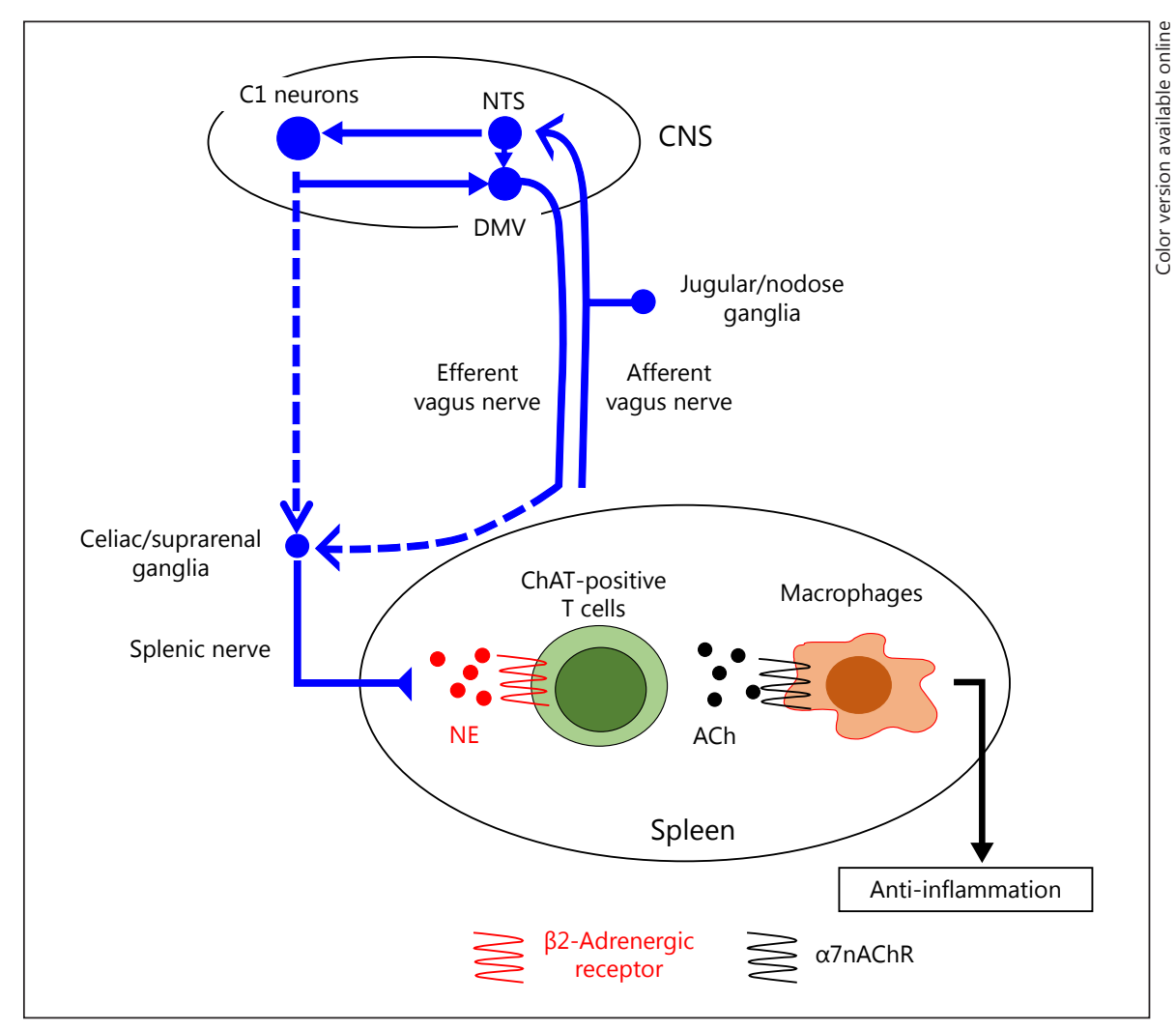

\section{Restrain Stress and Optogenetic Stimulation of C1}

Neurons: Is Stress Good for the Kidney?

Optogenetics is an emerging technique that regulates the activity of neurons. It allows for targeted excitation or inhibition with cellular specificity that is not feasible with electrical stimulation. In optogenetic stimulation, lightreactive membrane proteins (e.g., channelrhodopsin) are expressed specifically in some neurons in transgenic mice or by injecting cre-dependent viral vectors. When a specific wavelength light (blue light in the case of channelrhodopsin) is applied to the target nerve in these mice, the opsins react to the light, resulting in selective activation or silencing of the target neurons [17].

By using this technique, our recent work has added some new aspects to the inflammatory reflex [18]. C1 neurons, residing in the medulla oblongata and innervating sympathetic efferents, dorsal motor nucleus of the vagus nerve, and paraventricular nucleus of the hypothalamus, mediate adaptive autonomic responses to various stressors (e.g., hypoxia, hypotension, and lipopolysaccharide) [19]. Optogenetic stimulation of C1 neurons protected mice from renal IRI, and the protective effect was dependent on the spleen, $\beta 2$-adrenergic receptors, and a7nAChRs, which indicates that the CAP is involved in the protective effect of $\mathrm{C} 1$ neuron stimulation. It is interesting that restraint stress for $10 \mathrm{~min}$ also protected the kidney from IRI, which was mediated by $\mathrm{C} 1$ neurons. Given that various physical stresses including restraint stress activate $\mathrm{C} 1$ neurons, these results indicate that physical stresses should be avoided as much as possible in studies of AKI because these stresses potentially cause a confounding effect. The protection was significantly decreased by ganglionic blockade but unaffected by subdiaphragmatic vagotomy or by corticosterone receptor blockade, suggesting that $\mathrm{C} 1$ neurons activate the CAP through a sympathetic, not a vagus, route (Fig. 1).

\section{Pulsed Ultrasound}

Pulsed ultrasound (US) is one of the promising nonpharmacological and noninvasive methods to prevent AKI. We showed that prior US application can protect kidneys from IRI in mice using a clinical US machine [20, 21]. US suppresses systemic inflammation and attenuates AKI probably through activating the CAP. This is supported by various experiments including splenectomy, splenocyte transfer, CD4 reconstitution in Rag1-deficient mice, which lack $\mathrm{T}$ and $\mathrm{B}$ lymphocytes, and $\alpha 7 \mathrm{nAChKO}$ mice experiments. Bone marrow chimera experiments 
further revealed that $\alpha 7 \mathrm{nAChRs}$ on hematopoietic, but not parenchymal cells, are responsible for mediating the protective effect of US [21]. The protective effect of US was also confirmed in a cecal ligation and puncture-induced sepsis model [21].

\section{Other Strategies}

Remote ischemic preconditioning (RIPC) is a technique for producing resistance to a subsequent sustained episode of ischemia after a brief episode of ischemia being applied in distant tissues or organs. In addition to animal studies, many clinical studies on human AKI have been done $[22,23]$. They mainly use a blood pressure cuff to briefly restrict blood flow to the lower limb or upper limb (total ischemic duration is $15-30 \mathrm{~min}$ ) [22]. The latest systematic review and meta-analysis show that RIPC significantly decreased the incidence of AKI from 23.3 to $11.5 \%$. They also found that RIPC significantly reduced the incidence of AKI in the contrast-induced AKI subgroup but not in the ischemia reperfusion-induced AKI subgroup.

Another interesting nonpharmacological approach to achieving prevention of inflammation is acupuncture. Recently, Torres-Rosas et al. [24] showed that sciatic nerve activation with electroacupuncture suppresses systemic inflammation and rescues mice from polymicrobial peritonitis induced by cecal ligation and puncture by activating the vagus nerve. They identified a new sciaticto-vagus neural circuit that does not require $\alpha 7 \mathrm{nAChRs}$ or $\beta 2$-adrenergic receptors, suggesting that the new circuit is different from the classical CAP. This new anti- inflammatory mechanism mediated by the sciatic and vagus nerves induces the production of dopamine from the adrenal glands and dopamine release contributes to the suppression of systemic inflammation. The activation of this new circuit has not been applied to other organs, but the effect seems promising for the kidneys.

\section{Conclusion}

Activating the CAP is an emerging therapeutic strategy against inflammatory diseases, including AKI. Several methods to activate the CAP, such as VNS and pulsed US, have successfully reduced inflammation in animal models. These strategies appear promising as a therapy for AKI, although its effectiveness and safety in humans should be confirmed in future clinical trials. Novel techniques (e.g., optogenetics) should help us to elucidate the mechanisms by which VNS and pulsed US activate the CAP and ameliorate the inflammation.

\section{Acknowledgments}

Research conducted for this publication was supported by the National Institute of Diabetes and Digestive and Kidney Diseases of the National Institutes of Health under award numbers R01DK085259, R01DK062324, and U18 EB021787.

\section{Disclosure Statement}

The authors have no conflicts of interest to declare.

\section{References}

1 Okusa MD, Rosner MH, Kellum JA, Ronco C; Acute Dialysis Quality Initiative XIII Workgroup: Therapeutic targets of human AKI: harmonizing human and animal AKI. J Am Soc Nephrol 2016;27:44-48.

2 Rabb H, Griffin MD, McKay DB, Swaminathan S, Pickkers P, Rosner MH, Kellum JA, Ronco C; Acute Dialysis Quality Initiative Consensus XIII Group: Inflammation in AKI: current understanding, key questions, and knowledge gaps. J Am Soc Nephrol 2016;27: 371-379.

3 Tracey KJ: Physiology and immunology of the cholinergic anti-inflammatory pathway. J Clin Invest 2007;117:289-296.

4 Watkins LR, Goehler LE, Relton JK, Tartaglia N, Silbert L, Martin D, Maier SF: Blockade of interleukin-1 induced hyperthermia by subdiaphragmatic vagotomy: evidence for vagal mediation of immune-brain communication. Neurosci Lett 1995;183:27-31.
5 Kramer AA, Postler G, Salhab KF, Mendez C, Carey LC, Rabb H: Renal ischemia/reperfusion leads to macrophage-mediated increase in pulmonary vascular permeability. Kidney Int 1999;55:2362-2367.

6 Bernik TR, Friedman SG, Ochani M, DiRaimo R, Ulloa L, Yang H, Sudan S, Czura CJ, Ivanova SM, Tracey KJ: Pharmacological stimulation of the cholinergic anti-inflammatory pathway. J Exp Med 2002;195:781788.

7 Hosoi T, Okuma Y, Matsuda T, Nomura Y: Novel pathway for LPS-induced afferent vagus nerve activation: possible role of nodose ganglion. Auton Neurosci 2005;120:104-107.

8 Rosas-Ballina M, Ochani M, Parrish WR, Ochani K, Harris YT, Huston JM, Chavan S, Tracey KJ: Splenic nerve is required for cholinergic anti-inflammatory pathway control of TNF in endotoxemia. Proc Natl Acad Sci U S A 2008;105:11008-11013.
9 Rosas-Ballina M, Olofsson PS, Ochani M, Valdés-Ferrer SI, Levine YA, Reardon C, Tusche MW, Pavlov VA, Andersson U, Chavan S, Mak TW, Tracey KJ: Acetylcholinesynthesizing $\mathrm{T}$ cells relay neural signals in a vagus nerve circuit. Science 2011;334:98101.

10 Wang $\mathrm{H}$, Yu M, Ochani M, Amella CA Tanovic M, Susarla S, Li JH, Wang H, Yang H, Ulloa L, Al-Abed Y, Czura CJ, Tracey KJ: Nicotinic acetylcholine receptor alpha7 subunit is an essential regulator of inflammation. Nature 2003;421:384388

11 Inoue $\mathrm{T}$, Abe $\mathrm{C}$, Sung SS, Moscalu $\mathrm{S}$ Jankowski J, Huang L, Ye H, Rosin DL, Guyenet PG, Okusa MD: Vagus nerve stimulation mediates protection from kidney ischemia-reperfusion injury through $\alpha 7 \mathrm{nAChR}+$ splenocytes. J Clin Invest 2016;126:19391952. 
12 Hoeger S, Fontana J, Jarczyk J, Selhorst J, Waldherr R, Krämer BK, Schnuelle P, Yard BA: Vagal stimulation in brain dead donor rats decreases chronic allograft nephropathy in recipients. Nephrol Dial Transplant 2014; 29:544-549.

13 Goldstein RS, Bruchfeld A, Yang L, Qureshi AR, Gallowitsch-Puerta M, Patel NB, Huston BJ, Chavan S, Rosas-Ballina M, Gregersen PK, Czura CJ, Sloan RP, Sama AE, Tracey KJ: Cholinergic anti-inflammatory pathway activity and high mobility group box-1 (HMGB1) serum levels in patients with rheumatoid arthritis. Mol Med 2007;13:210-215.

14 Koopman FA, Chavan SS, Miljko S, Grazio S, Sokolovic S, Schuurman PR, Mehta AD, Levine YA, Faltys M, Zitnik R, Tracey KJ, Tak PP: Vagus nerve stimulation inhibits cytokine production and attenuates disease severity in rheumatoid arthritis. Proc Natl Acad Sci U S A 2016;113:8284-8289.

15 Pellissier S, Dantzer C, Mondillon L, Trocme C, Gauchez AS, Ducros V, Mathieu N, Toussaint B, Fournier A, Canini F, Bonaz B: Relationship between vagal tone, cortisol, TNF- alpha, epinephrine and negative affects in Crohn's disease and irritable bowel syndrome. PLoS One 2014;9:e105328.

16 Bonaz B, Sinniger V, Hoffmann D, Clarençon D, Mathieu N, Dantzer C, Vercueil L, Picq C, Trocmé C, Faure P, Cracowski JL, Pellissier S: Chronic vagus nerve stimulation in Crohn's disease: a 6-month follow-up pilot study. Neurogastroenterol Motil 2016;28:948-953.

17 Montgomery KL, Iyer SM, Christensen AJ, Deisseroth K, Delp SL: Beyond the brain: optogenetic control in the spinal cord and peripheral nervous system. Sci Transl Med 2016; 8:337rv335.

18 Abe C, Inoue T, Inglis MA, Viar KE, Huang L, Ye H, Rosin DL, Stornetta RL, Okusa MD, Guyenet PG: C1 neurons mediate a stress-induced anti-inflammatory reflex in mice. Nat Neurosci 2017;20:700-707.

19 Guyenet PG, Stornetta RL, Bochorishvili G, Depuy SD, Burke PG, Abbott SB: C1 neurons: the body's EMTs. Am J Physiol Regul Integr Comp Physiol 2013;305:R187-R204.

20 Gigliotti JC, Huang L, Ye H, Bajwa A, Chattrabhuti K, Lee S, Klibanov AL, Kalantari K,
Rosin DL, Okusa MD: Ultrasound prevents renal ischemia-reperfusion injury by stimulating the splenic cholinergic anti-inflammatory pathway. J Am Soc Nephrol 2013;24: 1451-1460.

21 Gigliotti JC, Huang L, Bajwa A, Ye H, Mace $\mathrm{EH}$, Hossack JA, Kalantari K, Inoue T, Rosin DL, Okusa MD: Ultrasound modulates the splenic neuroimmune axis in attenuating AKI. J Am Soc Nephrol 2015;26:2470-2481.

22 Ho PW, Pang WF, Szeto CC: Remote ischaemic pre-conditioning for the prevention of acute kidney injury. Nephrology (Carlton) 2016;21:274-285.

$23 \mathrm{Hu}$ J, Liu S, Jia P, Xu X, Song N, Zhang T, Chen R, Ding X: Protection of remote ischemic preconditioning against acute kidney injury: a systematic review and meta-analysis. Crit Care 2016;20:111.

24 Torres-Rosas R, Yehia G, Peña G, Mishra P, del Rocio Thompson-Bonilla M, Moreno-Eutimio MA, Arriaga-Pizano LA, Isibasi A, Ulloa L: Dopamine mediates vagal modulation of the immune system by electroacupuncture. Nat Med 2014;20:291-295. 